\title{
Construction of CTC-ALK gene fusion detection system based on the multi- site magnetic separation in lung cancer and its clinical verification
}

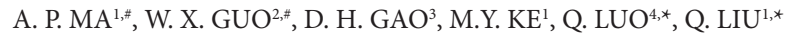 \\ ${ }^{1}$ Department of Respiratory and Critical Medicine, School of Medicine, The First Affiliated Hospital of Xiamen University, Xiamen, Fujian, \\ China; ${ }^{2}$ Department of Thoracic Surgery, School of Medicine, The First Affiliated Hospital of Xiamen University, Xiamen, Fujian, China; ${ }^{3}$ De- \\ partment of Pathology, School of Medicine, The First Affiliated Hospital of Xiamen University, Xiamen, Fujian, China; ${ }^{4}$ Department of Gastro- \\ intestinal Surgery, School of Medicine, The First Affiliated Hospital of Xiamen University, Xiamen, Fujian, China.
}

*Correspondence: docluoqi@163.com; 385653071@qq.com

${ }^{*}$ Contributed equally to this work.

Received February 21, 2020 / Accepted May 28, 2020

\begin{abstract}
Detected in a variety of solid tumors, including lung cancer, the EML4-ALK fusion gene plays an important role in promoting the occurrence and development of cancer. The existing detection methods for EML4-ALK fusion gene are all targeted at surgical or post-sampling tumor tissues, which cannot achieve early detection and real-time monitoring; therefore, a minimally invasive ALK gene fusion detection system is explored and constructed. Vimentin, EpCAM, and EGFR antibodies were grafted, respectively, to prepare multi-site immunoliposome magnetic beads, so as to capture CTC in blood for RT-PCR detection, and then the feasibility of this method was verified by detecting the positive rate of the EML4-ALK fusion gene and clinical information in combination with WB and IHC. The prepared multi-site immunoliposome magnetic beads showed high specificity and stability, and the average proliferation rate and capture rate of cells were $95 \%$ and $85 \%$, respectively. In clinical blood samples, the CTC level of the grade I (G1) patients before the operation was lower than grade 2 (G2), and that of grade II (G2) was significantly lower than grade III (G3), but the difference was not significant after the operation. The RT-PCR results of CTC and the RT-PCR, WB, and IHC results of tissues were highly consistent in the fusion gene detection, and the positive rate of ALK gene fusion in 60 lung cancer patients was $31.67 \%$ and $28.33 \%$ before and after the operation, mostly EML4-ALK (V3) gene fusion. The CTC-ALK gene fusion detection system constructed successfully could avoid the problem of difficult sampling and post-sampling complications, and truly achieve the minimally invasive biopsy, so it was of important clinical significance for the diagnosis and efficacy evaluation of lung.
\end{abstract} biopsy

Key words: lung cancer, immunomagnetic beads, circulating tumor cells (CTCs), EML4-ALK fusion gene, minimally invasive

The incidence and mortality of lung cancer have ranked the first among malignant tumors both in China and the whole world. According to the statistics of global cancer epidemic released by the International Agency for Research on Cancer (IARC) (GLOBOCAN 2012), there were about 1.82 million new cases and 1.59 million death cases of lung cancer in 2012, accounting for $13 \%$ and $19 \%$ of new cases and death cases of malignant tumors respectively $[1,2]$. The high incidence and mortality of lung cancer are closely related to the unknown pathogenesis of lung cancer, at the same time effective means of prevention and treatment are still lacking.

People's understanding of the pathogenesis of cancer has gradually risen to the nucleic acid level with the development of molecular medicine and the advance of gene technology. Once mutated, the key genes regulating cell growth, prolif- eration, apoptosis, and other life processes will cause unlimited cell proliferation and distant metastasis, thereby eventually leading to carcinogenesis. Such genes are called "cancer driver genes", namely, the nucleic acid molecular changes that promote the generation of cancer cells and maintain their malignant phenotypes [3-5]. The research on the driver genes of lung cancer has made remarkable achievements, especially in lung adenocarcinoma, about $60 \%$ of the driver genes have been identified, such as mutation of EGFR, KRAS, HER2, PIK3CA, BRAF, and MET genes, and rearrangement of ALK, ROS1, and RET genes [6], as a new driver gene of NSCLC, EML4-ALK fusion gene is mainly composed of an inverted EML4 fragment connected to residual ALK fragments, belonging to the paracentric interchange in the same chromosome [7], of which the coiled-coil structure of EML4 can 
mediate dimerization, thereby promoting the autophosphorylation of ALK, activating ALK tyrosine kinase, and enabling EML4-ALK fusion protein to play a role in the carcinogenic transformation of cells [8]. Therefore, the correct diagnosis of the fusion gene is very essential for effective treatment later. The fusion gene detection methods mainly include: fluorescence in situ hybridization (FISH), whose specificity is relatively high, and the detection results are considered as the "gold standard" for the detection of ALK fusion gene [9]. The immunohistochemical assay is a relatively fast and affordable detection method, but this method is mostly used for tissue, and the results of IHC are identified by human eyes for the staining intensity of sections. The results are determined by the scoring system, which may be interfered with by human factors. Compared with the two methods above, RT-PCR method is simple to operate, especially when the fusion sites of known fusion genes are amplified, RT-PCR technique can be used as a detection method to screen a specific type of fusion gene [10-12]. Nevertheless, the detection methods above are mostly used for tissue detection, it is difficult to acquire the tissue sample; currently, there are few reports on EML4-ALK gene fusion through CTC liquid biopsy.

Therefore, EML4-ALK gene fusion in CTCs was studied and detected by RT-PCR after the specific immunoliposome magnetic beads were prepared to capture the CTCs in blood, and then the verification was performed in combination with the immunohistochemical method and western blot, thus establishing a minimally invasive liquid biopsy system. It would determine a guiding significance for clinical research whether the detection of EML4-ALK fusion gene could be achieved by CTCs.

\section{Patients and methods}

Specimens. Peripheral blood samples and tumor tissues of 60 patients with lung cancer diagnosed by pathology in our hospital from July 2017 to December 2019 were collected. Patients in the group need to agree to receive PET-CT evalu- ation before treatment, aged between 18 and 75 years old, ECOG score $0-1$, can be followed up; excluding patients with severe anemia or organ dysfunction, patients with active infection, and previous malignant tumors. The method of collecting blood samples is to collect $7.5 \mathrm{ml}$ of peripheral blood into medical anticoagulant (K2-EDTA) blood vessels. The tumor tissues of lung cancer and paraffin-embedded tissues were fixed in formalin, embedded in paraffin, cut into $4 \mu \mathrm{m}$ thick slices, placed on glass slides, and baked to dry in preparation for IHC experiment. This study was approved by the Ethics Committee of our college. Participants gave written consent after receiving verbal and written information (2020GKJ017).

Materials and instruments. Human lung cancer cell line A549 and human normal lung epithelial cell line BEAS-2B were obtained from the Shanghai Cell Bank of Chinese Academy of Sciences; 1, 2-dioleyl phosphatidylcholine (DOPC), dimethyl-octadecyl epoxypropyl chloride (GHDC), cholesterol, N-hydroxysuccinimide (NHS), 1-ethyl-3 -(3-dimethylammonium propyl) ammonium bicarbonate (EDC) were purchased from Sinopharm Group; EpCAM antibodies, Vimentin, and EGFR antibodies were purchased from CST; $\mathrm{Fe}_{3} \mathrm{O}_{4}$ solution, carboxymethyl chitosan hexadecyl quatriamine salt (HQCMC), CK-FITC, CD45-PE, and DAPI were purchased from Huzhou Liyuan Medical Laboratory Co., Ltd.; TRIzol Reagent for RNA extraction was purchased from Ambion, USA; GoScriptTM Reverse Transcription System was purchased from Promega (Beijing) Biotechnology Co., LTD. BCA protein detection kit was purchased from Thermo Fisher; 96-well PCR apparatus was purchased from Bio-Rad, USA; Bi-90Plus laser granulometer/Zeta potentiometer was purchased from Brookhaven Instrument Corporation, USA; OLYMPUS B $\times 61$ fluorescence microscope was purchased from OLYMPUS, Japan; Multifunctional microplate reader SpectraMax ${ }^{\odot}$ M5/M5e was purchased from Molecular Devices, USA ; LDJ9600-1 VSM magnetic tester was purchased from Digital Equipment Corporation, USA.

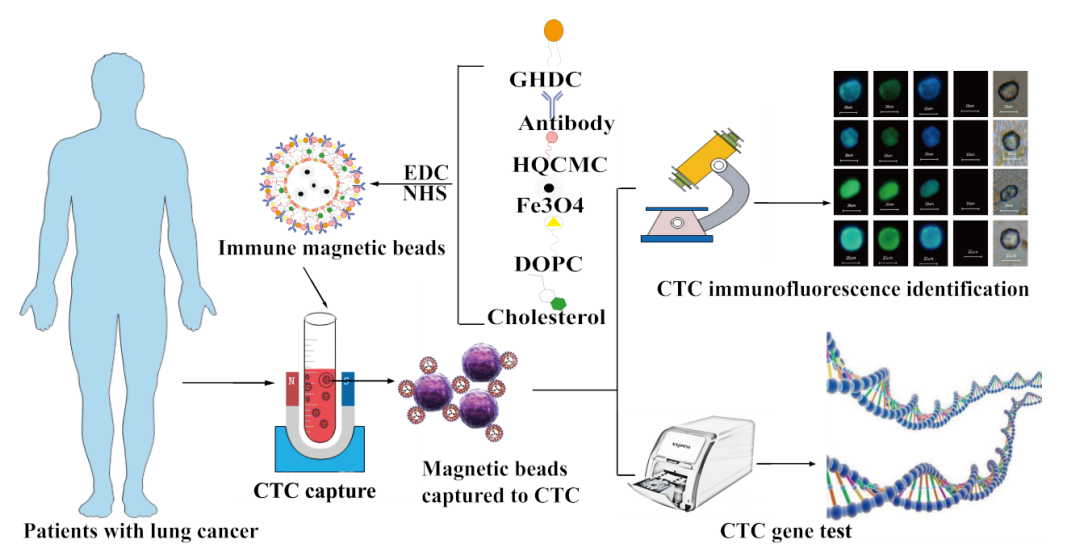

Figure 1. Capture and identification of CTCs in clinical blood samples. 
Preparation of multi-site immunoliposome magnetic beads. Three kinds of micro-nano liposome immunomagnetic beads were prepared by a reverse evaporation method. For example, VI-LMB (vimentin liposome magnetic bead): with liposome dichloromethane as the co-solvent, and cholesterol, DOPC, GHDC, HQCMC as the preparation materials of liposome substrate. $\mathrm{Fe}_{3} \mathrm{O}_{4}$ was suspended in the PBS solution ( $\mathrm{pH} 7.4,0.1 \mathrm{~mol} / \mathrm{l}$ ), added into the liposome substrate, and then the ultrasonic oscillation of mixed solution was made by using the probe-type ultrasonic instrument. The ultrasonic time was $10 \mathrm{~min}$, the temperature $25^{\circ} \mathrm{C}$, and the power $27 \%$, to achieve complete emulsification, thus obtaining LMB (liposome magnetic bead). The coupling N-hydroxysuccinimide (NHS) and 1-ethyl-3-(3dimethylaminopropyl)carbodiimide (EDC) were added respectively after a $0.6 \mathrm{mg}$ vimentin antibodies addition in $10 \mathrm{ml}$ isopropyl alcohol. The mixed solution was stirred at a $100 \mathrm{rpm} / \mathrm{min}$ for 24 hours at $4^{\circ} \mathrm{C}$ so that the liposome magnetic beads modified by vimentin antibodies could be obtained (VI-LMB). Then an aseptic dry EP tube with the specification of $2 \mathrm{ml}$ was weighed, and the prepared VI-LMB were transferred to it, weighed again after magnetic separation, which was diluted with distilled water to $1 \mathrm{mg} / \mathrm{ml}$ for a standby. The preparation methods of EP-LMB (EpCAM liposome magnetic bead) and EGFR-LMB (EGFR liposome magnetic bead) were the same as that of VI-LMB.

The prepared VI-LMB, EP-LMB, EGFR-LMB were subject to ultraviolet absorption spectrum scanning by using an ultraviolet spectrophotometer, with the magnetization tested by magnetic measurement system (MPMS), the particle size and potential detected by BI-90 Plus laser granulometer/Zeta potentiometer, and the morphology was observed by atomic force microscopy (AFM).

Cytotoxicity test. A549 cell line was cultured in an incubator $\left(5 \% \mathrm{CO}_{2} ; 37^{\circ} \mathrm{C}\right)$ in 1640 culture medium that contained $10 \%$ FBS, $1 \%$ penicillin $(100 \mathrm{U} / \mathrm{ml})$, and $1 \%$ streptomycin $(100 \mathrm{U} / \mathrm{ml})$. When the cell density reached $80 \%$ or so, the cells were dissolved to suspension, counted in a blood counting chamber, and then the cells were transfered to the 96-well plate (1,000 cells/well), with $200 \mu$ of the culture medium. After the cells were treated with the addition of magnetic beads, the concentrations of VI-LMB, EP-LMB, and EGFR-LMB were $10 \mu \mathrm{g} / \mathrm{ml}, 20 \mu \mathrm{g} / \mathrm{ml}, 30 \mu \mathrm{g} / \mathrm{ml}, 40 \mu \mathrm{g} / \mathrm{ml}$, $50 \mu \mathrm{g} / \mathrm{ml}$, and $60 \mu \mathrm{g} / \mathrm{ml}$, respectively, with $1 \%$ DMSO as the control group. MTT assay was conducted after the 96-well plates were cultured in a $\mathrm{CO}_{2}$ incubator for $72 \mathrm{~h}$, with $20 \mu \mathrm{l}$ MTT added to each well. After incubation in a $\mathrm{CO}_{2}$ incubator for $2 \mathrm{~h}$, the absorbance of each well at the light wavelength of $560 \mathrm{~nm}$ was measured by full-wavelength microplate reader to calculate the cell proliferation rate. The group with the highest proliferation rate was selected for repeated test for one week, and the growth curve was drawn.

Cell capture efficiency test. A549 cells suspension was prepared after digestion and cell density was determined with a hemocytometer, and divided into PBS group and blood simulation group, with 100 A549 cells in both $7.5 \mathrm{ml}$ PBS and normal blood, in addition to $20 \mu \mathrm{l}$ VI-LMB (3932S), EP-LMB (3599S) and EGFR-LMB (2232S), respectively. Each kind of magnetic beads was a set with three replicates. Magnetic separation and counting were performed immediately after capturing the $20 \mathrm{~min}$, and the captured cells were counted with FITC-labeled CK19 monoclonal antibody (CK19-FITC), DAPI staining fluid, PE-labeled CD45 antibody (CD45-PE) for the calculation of capture efficiency. In addition, the three PBS replicates and three blood replicates were captured by VI-LMB and then EP-LMB and EGFR-LMB successively. Subsequently, the total capture efficiency of three magnetic beads in blood and PBS was compared, and the distribution of the captured cells on the cell surface was observed by Prussian staining. The cells were smeared and fixed in $4 \%$ paraformaldehyde for $10 \mathrm{~min}$. The smears were filled with prepared Perls stain and $30 \mathrm{~min}$ incubated at $37^{\circ} \mathrm{C}$, washed twice with distilled water, 2 min each time. The smears were dyed with Perls re-staining solution for 1 minute, washed, dried, and examined under the microscope.

Capture and identification of CTCs in clinical blood samples. The peripheral blood of 60 patients $(7.5 \mathrm{ml})$ was divided into two groups, which were first captured by VI-LMB, and then EP-LMB and EGFR-LMB. One group was stained for $15 \mathrm{~min}$ in the dark after evenly mixed with $10 \mathrm{ml}$ FITC-labeled CK19 monoclonal antibody (CK19-FITC), 20 $\mathrm{ml}$ DAPI staining fluid, and $10 \mathrm{ml} \mathrm{PE}$-labeled CD45 antibody (CD45-PE). After staining, the magnetic beads were washed with $1 \mathrm{ml}$ dd water, and then the solution was discarded after magnetic separation. The magnetic beads were washed 2 times, and $20 \mathrm{ml}$ deionized water was added to the centrifuge tube for mixing, which was evenly applied on the anti-off slide treated with polylysine. Finally, the observation and counting were made under the fluorescence microscope after the liquid drops became dry. The other group was merged with the cells captured by three kinds of magnetic beads, which was added with $20 \mathrm{ml}$ PBS and kept in the refrigerator at $4{ }^{\circ} \mathrm{C}$ for EML4-ALK fusion gene detection.

EML4-ALK fusion gene detection. Reverse Transcription-Polymerase Chain Reaction (RT-PCR): RNA was extracted from lung cancer tumor tissues and tumor cells by TRIzol method. After quantified, the RNA extracted from tumor tissues and tumor cells was reverse-transcribed into cDNA according to the user's instruction manual of Promega reverse transcription kit. $\mathrm{PCR}$ reaction was made with the specific primers designed for fusion sites by using CDNA as the template, with the primer sequence as follows: EML4-ALK V1: forward 5'-GGGGAATGGAGATGTTCTTACTG-3', reverse 5'-GAGCTTGCTCAGCTTGTACTCAG-3'; EML4-ALK V2: forward 5'-GCTACATCACACACCTTGACTGG-3', reverse 5'-GAGCTTGCTCAGCTTGTACTCAG-3';EML4-ALK V3: forward 5'-AAATTGTCGAAAATACCTTCAACAC-3', reverse 5'-GAGCTTGCTCAGCTTGTACTCAG-3'; EML4-ALK V4: forward 5'-upstream CACTTTGTCAGATGAGAAATGGG-3', reverse 5'-GAGCTTGCTCAGCTT- 
GTACTCAG-3'; EML4-ALK V5: forward 5'-GATGAAATCACTGTGCTAAAGGC-3', reverse 5'-GAGCTTGCTCAGCTTGTACTCAG-3'; GAPDH: forward 5'-TGAAGGTCGGAGTCAACGGAT-3', reverse 5'-CTGGA-AGATGGTGATGGGATT-3'. OneStep RT-PCR kit (Qiagen, Inc., Valencia, CA, USA) was used for the RT-qPCR, which was performed in an ABI 7500 (Thermo Fisher Scientific, Inc.). The thermocycling conditions were $95^{\circ} \mathrm{C}$ for $5 \mathrm{~min}$, and 40 cycles at $95^{\circ} \mathrm{C}$ for $15 \mathrm{sec}$, and $60^{\circ} \mathrm{C}$ for $15 \mathrm{sec}$. GAPDH was used as an internal reference for EML4-ALK.

Immunohistochemistry (IHC). The samples on slides embedded with paraffin and formalin were firstly dewaxed in xylene and rehydrated in alcohol gradients of 100\%, 95\%, $85 \%$, and $75 \%$. The slides were then heated to $95^{\circ} \mathrm{C}$ for $30 \mathrm{~min}$ to retrieve antigens in the tissues. The activity of endogenous peroxidase was blocked by employing $3 \%$ hydrogen peroxide for $10 \mathrm{~min}$. Part of the tissue was covered with normal serum at room temperature for $30 \mathrm{~min}$. The primary antibody was added and incubated at $4{ }^{\circ} \mathrm{C}$ overnight, followed by the secondary antibody incubation for $10 \mathrm{~min}$. Next, the samples were stained with 3,3'-diaminobenzidine and counterstained with hematoxylin. The procedure of dehydration was implemented and finally, covers slips were applied.

Western blotting (WB). An appropriate amount of tissue was ground into powder, PMSF, phosphatase inhibitor, and protease inhibitor were added followed by the ultrasonication for 15 seconds under the power of 30 . After centrifugation at $4{ }^{\circ} \mathrm{C}$ for $30 \mathrm{~min}$ at $12000 \mathrm{rpm}$, the proteins in the supernatant were obtained and separated by $8 \%$ sodium dodecyl sulfate-polyacrylamide gel electrophoresis. Proteins were then transferred onto a polyvinylidene difluoride membrane (Millipore). Membranes were blocked in Trisbuffered saline-Tween containing 5\% nonfat dry milk and $\beta$-actin (1:2,000; Santa Cruz Biotechnology) antibodies. Relative expression levels were quantified using Quantity One software (Bio-Rad).

Statistical approach. SPSS21.0 statistical software was used for the analysis, with the data expressed as mean \pm standard deviation. One-way ANOVA was used for the comparison between time points, the SNK test was used for pairwise comparison, and the $t$ test was used for comparison between two groups, with $<0.05\left({ }^{*} \mathrm{p}<0.05\right.$; ${ }^{* *} \mathrm{p}<0.01$; $\left.{ }^{* * *} \mathrm{p}<0.001\right)$ considered as statistically significant.

\section{Results}

Characterization of immunoliposome magnetic beads. The characterization results of the three kinds of magnetic beads (Figures 2A-C) show the particle size distribution of VI-LMB, EP-LMB, and EGFR-LMB respectively, with the average particle size of $251.1 \pm 1.5 \mathrm{~nm}, 236.6 \pm 2.5 \mathrm{~nm}$, and $243.3 \pm 1.2 \mathrm{~nm}$, respectively. Figures $2 \mathrm{D}-\mathrm{F}$ show the potential distribution of the three kinds of magnetic beads that are are positively charged, which is conducive to the dispersion of magnetic beads in hydrophilic solution. According to the observation results from AFM (atomic force microscopy) in Figure 2G, the three kinds of magnetic beads are spherical in different sizes, with relatively regular shape and no agglomeration, which is consistent with the particle size test results. According to the UV scanning results of the three kinds of magnetic beads shown in Figure $2 \mathrm{H}$, there is no absorption peak at $280 \mathrm{~nm}$ for LMB, but the absorption peak appears at $280 \mathrm{~nm}$ for VI-LMB, EP-LMB, and EGFR-LMB, which is just the characteristic of ultraviolet absorption protein, indicating that the magnetic beads were coated with EpCAM, EGFR, and Vimentin antibodies on the surface. As shown in Figure 2I, the magnetic hysteresis curves of VI-LMB, EP-LMB, and EGFR-LMB, the naked magnetic beads $\mathrm{Fe}_{3} \mathrm{O}_{4}$ had the highest saturation magnetization intensity, followed by those coated with liposome, and then those modified by the antibody. The results of contrast analysis show that the saturation magnetization intensity of $\mathrm{Fe}_{3} \mathrm{O}_{4}$ after coated by DOPC is weakened to some extent, and even lower after coupled with antibody, suggesting that magnetic beads $\mathrm{Fe}_{3} \mathrm{O}_{4}$ were coated by liposome and modified by antibody successfully.

Cytotoxicity. Figure 3A shows the cell proliferation rates after treatment with three kinds of magnetic beads, VI-LMB, EP-LMB, EGFR-LMB, at different concentrations, and it could be seen from the figure that A549 cell proliferation rate was greater than $80 \%$ when the concentrations of the three kinds of magnetic beads were below $30 \mu \mathrm{g} / \mathrm{ml}$, and there was no significant difference from the control group (DMSO group) at the concentration of $20 \mu \mathrm{g} / \mathrm{ml}$. The cell proliferation rate decreased as the concentration of magnetic beads increased, suggesting that the magnetic beads at too high concentration showed certain toxicity to cells, but the proliferation rate remained above $60 \%$. The growth curve of A549 cells treated with $20 \mu \mathrm{g} / \mathrm{ml}$ magnetic beads was further measured experimentally, as shown in Figure 3B, and there was no significant difference between the growth curve of the three magnetic beads and that of the control group in the continuous determination for a week, indicating that the effect of the three kinds of magnetic beads on cytotoxicity was stable, which would not increase with the growth of culture time.

Cell capture efficiency. In the simulated capture of CTCs in vitro, the cells captured were subjected to Prussia staining simultaneously, with the results shown in Figure 4A. As could be seen from Figure 4A, the liposome magnetic beads not modified by antibodies were scattered around the cells, while the antibody-modified VI-LMB, EP-LMB, EGFR-LMB magnetic beads were attached on the cell surface, indicating the antibody-modified VI-LMB, EP-LMB, EGFR-LMB could make immunological recognition of cells, which was consistent with the UV test results. Figure 4B shows the cell capture rates of the three kinds of magnetic beads in the blood and PBS system, and the figure shows three kinds of magnetic beads in the blood or PBS capture rate were not significantly different $(\mathrm{p}>0.05)$. The capture rate of 
A

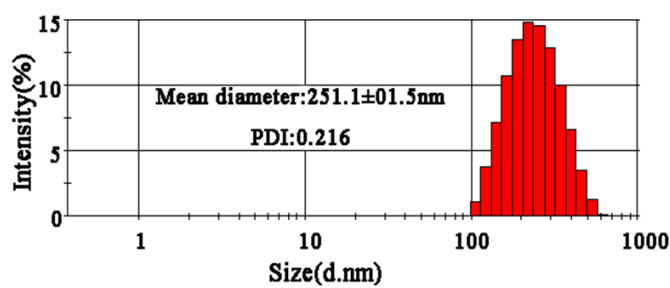

B

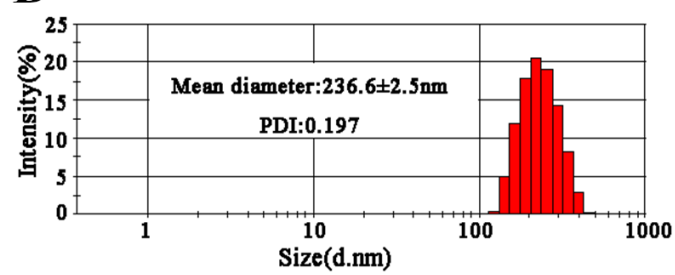

C

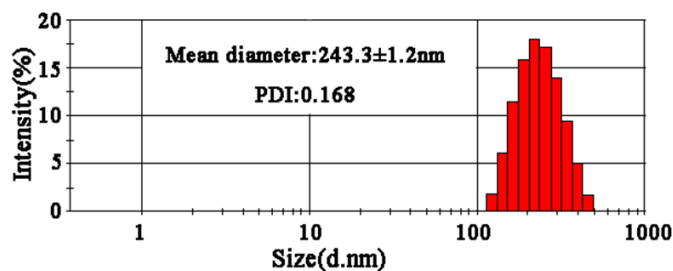

G

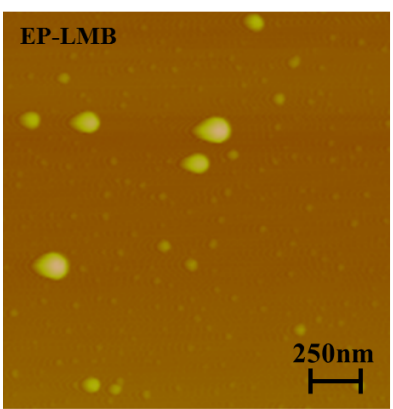

$\mathbf{H}$

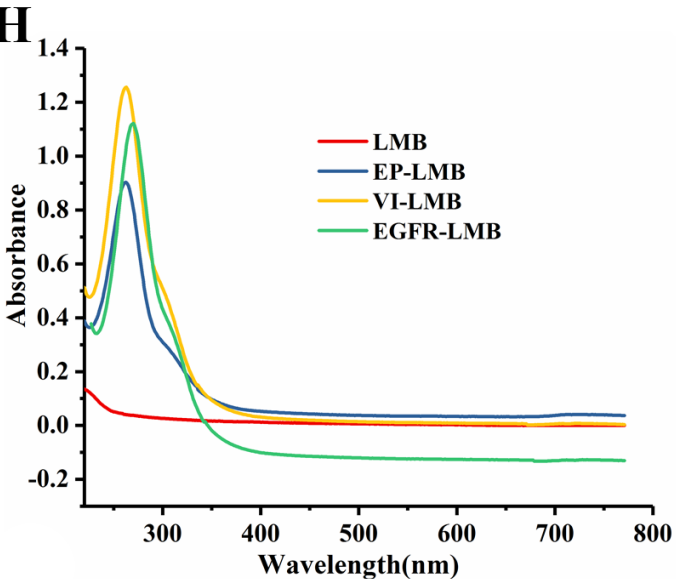

D
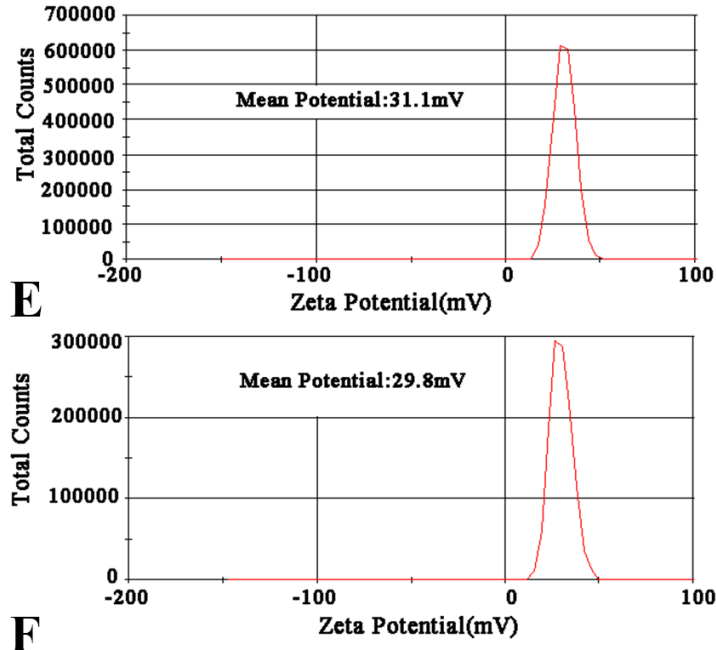

$\mathbf{F}$

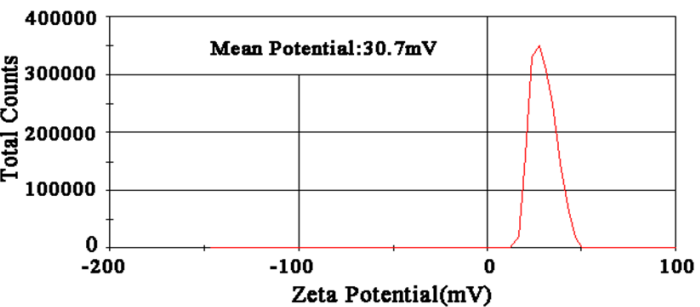

Zeta Potential(mV)
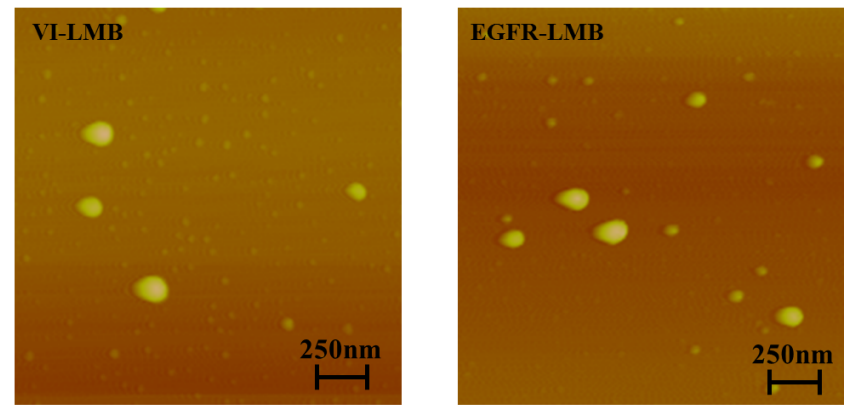

I

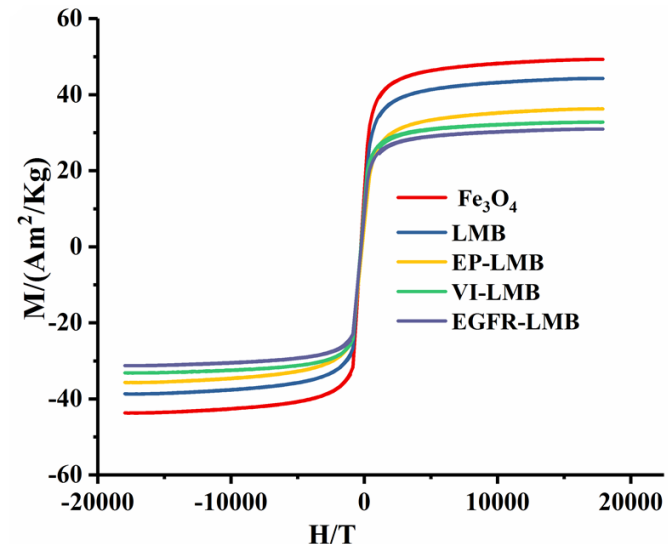

Figure 2. Characterization of three kinds of immunomagnetic beads. A) EP-LMB particle size distribution; B) VI-LMB particle size distribution; C) EGFR-LMB particle size distribution; D) EP-LMB potential test diagram; E) VI-LMB potential test diagram; F) EGFR-LMB potential test diagram; G) Atomic force test results of three kinds of immunomagnetic beads; H) Ultraviolet scanning spectra of three kinds of magnetic beads; I) Hysteresis cycle curve $B$. 

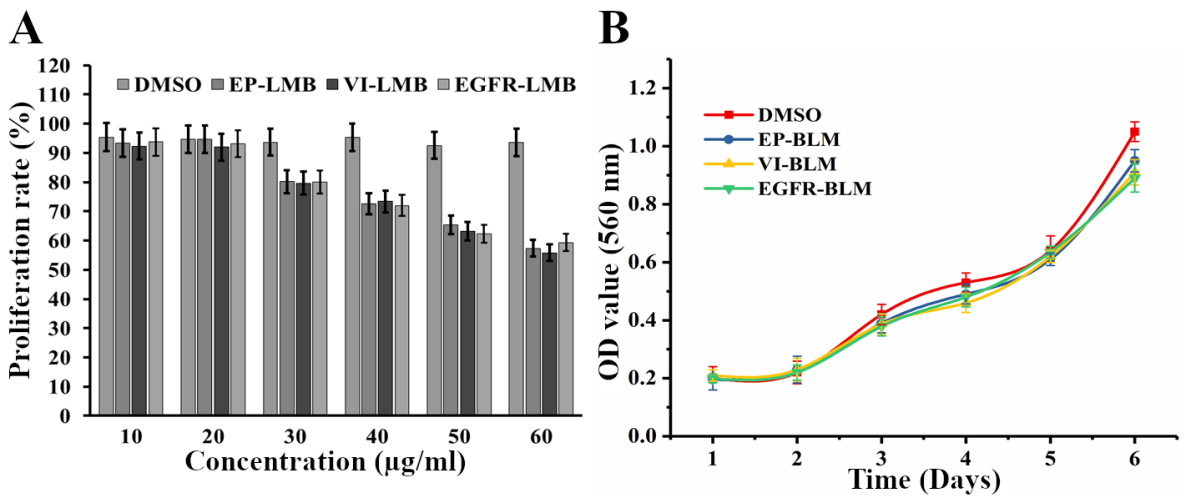

Figure 3. Effect of three kinds of immunomagnetic beads on A549 cell activity. A) Effect of different concentrations of the three kinds of immunomagnetic beads on A549 cell proliferation rate; B) A549 cell growth curve treated with $20 \mu \mathrm{g} / \mathrm{ml}$ magnetic beads.

A

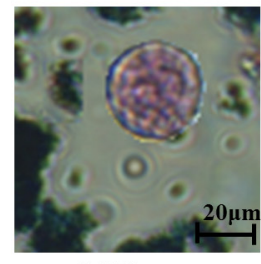

LMB

B

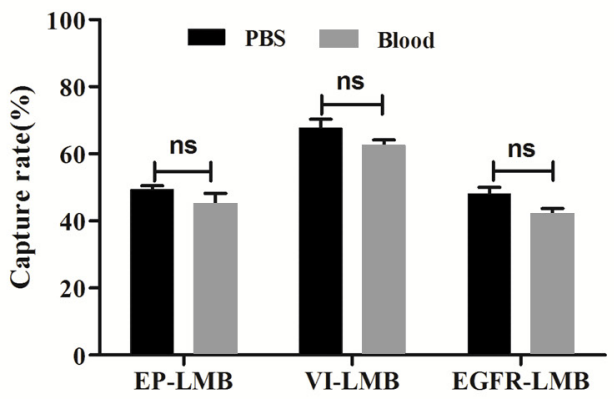

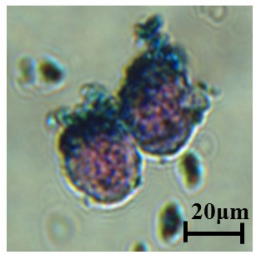

EP-LMB

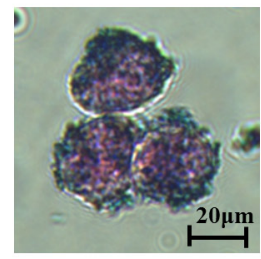

VI-LMB

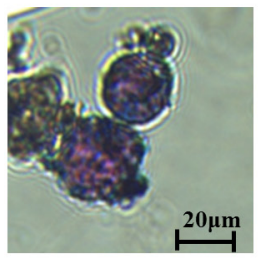

EGFR-LMB

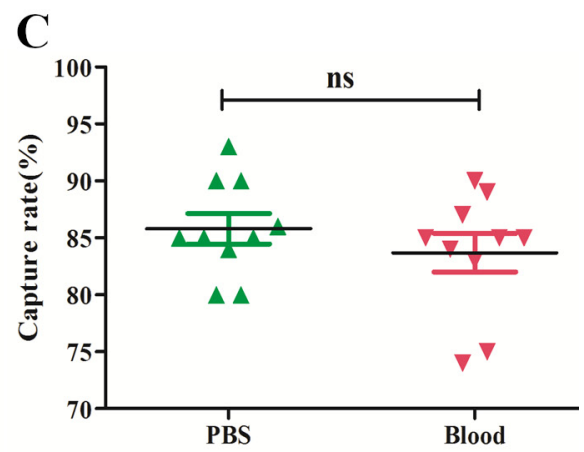

Figure 4. Simulated CTC capture efficiency of the three kinds of magnetic beads in vitro. A) Distribution of the three kinds of magnetic beads on the cell surface; B) Cell capture efficiency of the three kinds of magnetic beads in PBS and blood system, respectively; C) Total cell capture rate of the three kinds of magnetic beads in PBS and blood system.

VI-LMB magnetic beads was greater than that of EP-LMB and EGFR-LMB, and the three kinds of magnetic beads showed better recognition ability and capture ability to cells, so the total cell capture rates in the same cell suspension by the three kinds of magnetic beads under different environment were investigated successively, with the results shown in Figure 4C. There was no significant difference in the total capture efficiency of the three kinds of magnetic beads in PBS and blood $(p>0.05)$, indicating that this method could be used to capture CTCs from the patient clinical blood sample.

CTCs captured in clinical blood samples and identification results. Except for CTCs, the cells after magnetic enrichment also include a certain number of erythrocytes and leukocytes. The CTC recognition is currently mainly based on CTC antigen specific expression; therefore, the identification of CTCs in this experiment was achieved by immunofluorescence staining. The cell morphology could be observed under white light, and it could be determined that the cell captured by magnetic beads in the blood was CTC when CK19-FITC green fluorescence was strongly positive, DAPI blue fluorescence was strongly positive, and CD45 staining was negative. Figure 5A shows the immunofluorescence identification of CTC in clinical blood captured by the three kinds of magnetic beads, and as shown in Figure 5A, all cells captured by the three kinds of magnetic beads are CTCs. Figure 5B shows the level of CTCs captured by the three magnetic beads in the blood of 60 patients 
before operation, with the average level of CTCs captured by VI-LMB magnetic beads significantly higher $(\mathrm{p}<0.05)$ than that of EP-LM and EGFR-LMB. The average level of CTCs captured by EGFR-LMB was significantly lower than that of EP-LM. Figure 5C shows the CTC level of patients with different tumor grades before the operation, in which the CTC level of well-differentiated grade 1 (G1) before the operation is lower than medium differentiation grade 2 (G2), and G2 is significantly lower than poorly differentiated grade 3 (G3), but there is no significant difference after the operation (Figure 5D).

Detection and verification of the EML4-ALK fusion gene. The detection and verification results of EML4-ALK fusion gene in three positive patients is shown in Figure 6. The AGE (agarose gel electrophoresis) of the EML4-ALK (V3) gene fusion by RT-PCR: CTC EML4-ALK (V3) fusion gene exists in CTC, with the result consistent with that in tissue (Figure 6B). Figure 6C shows the expression results of the fusion protein in tumor tissue of the patient by western blot. The ALK protein specific band appears at about $86 \mathrm{kDa}$, indicating that ALK fusion occurs in this patient. Figures $6 \mathrm{D}$ and $6 \mathrm{E}$ show the immunohistochemical results, in which the cytoplasm of tumor cells show dark brown, namely, positive results (Figure 6E), with para-tumor tissue selected as the negative control (Figure 6D); the comparison of several methods could prove that EML4-ALK gene fusion could be detected by capturing CTCs.

The relationship between EML4-ALK and clinicopathological parameters and the statistical results of gene fusion. The CTCs captured in the peripheral blood samples of 60 patients were subject to the EML4-ALK fusion gene detection, and a total of 19 EML4-ALK genes were found to be
A

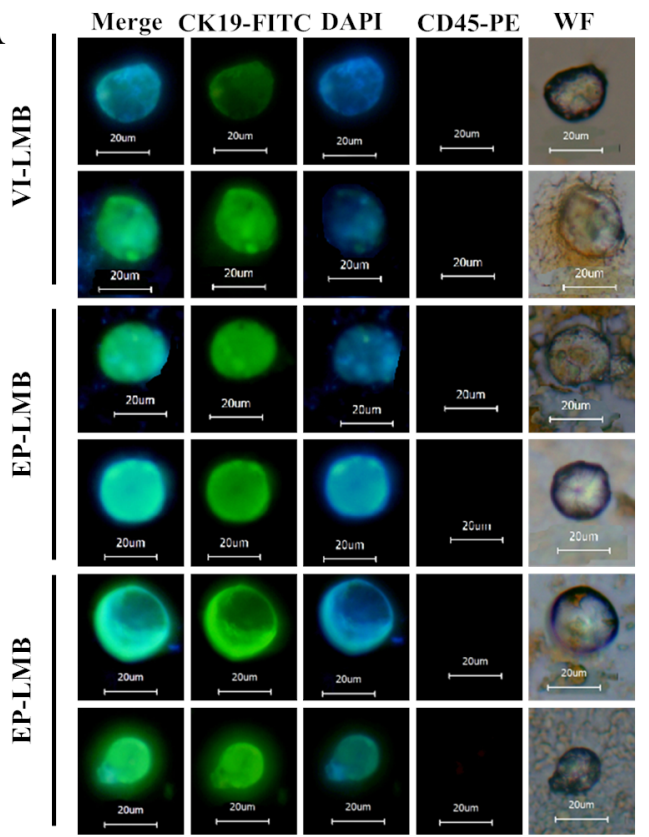

B

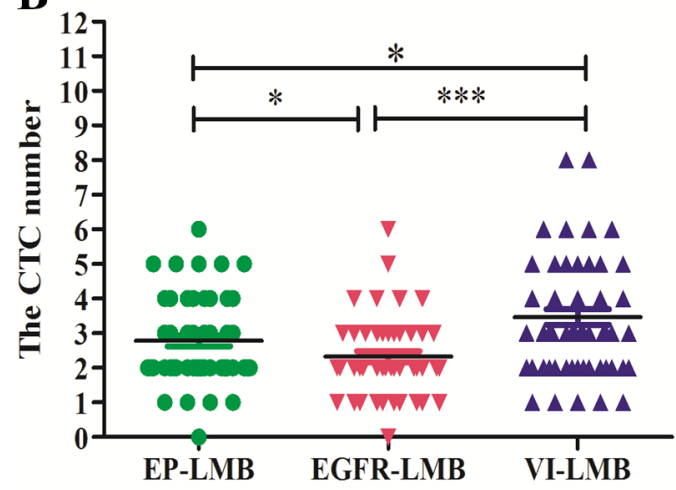

C

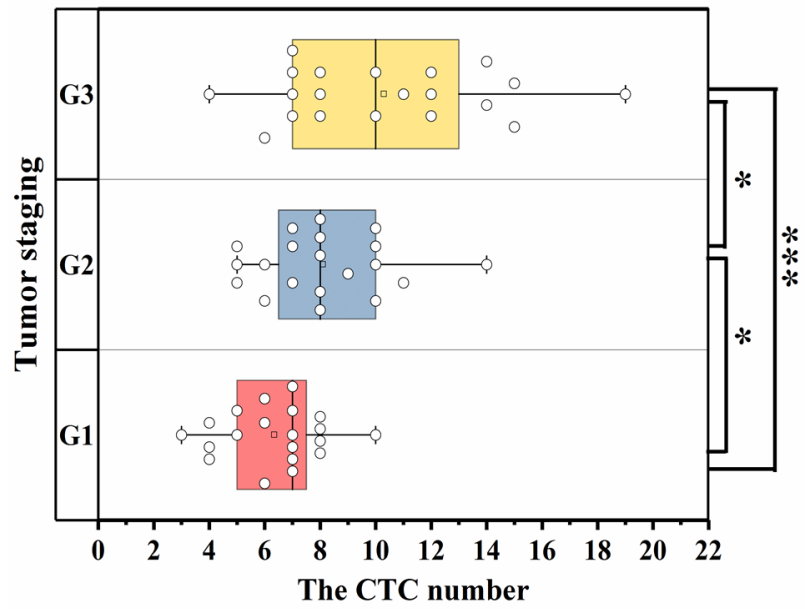

D

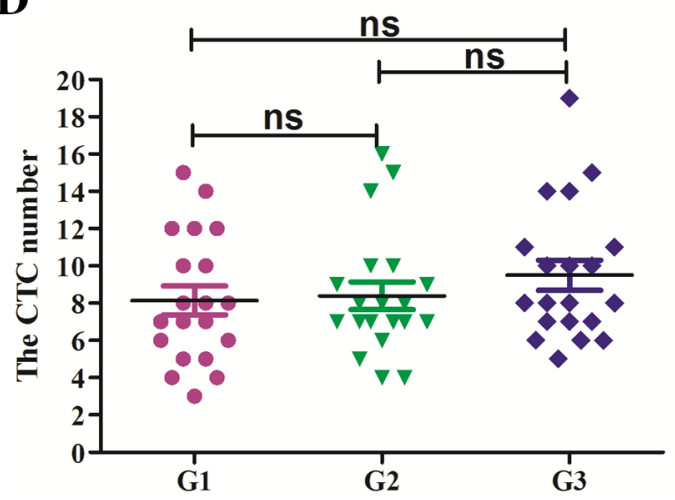

Figure 5. CTCs captured in clinical blood samples and identification results. A) CTC immunofluorescence identification results (scale: $20 \mathrm{~cm}$ ); B) CTC levels captured by the three kinds of magnetic beads; C) Pre-operative CTC distribution level; D) Post-operative CTC distribution level. 

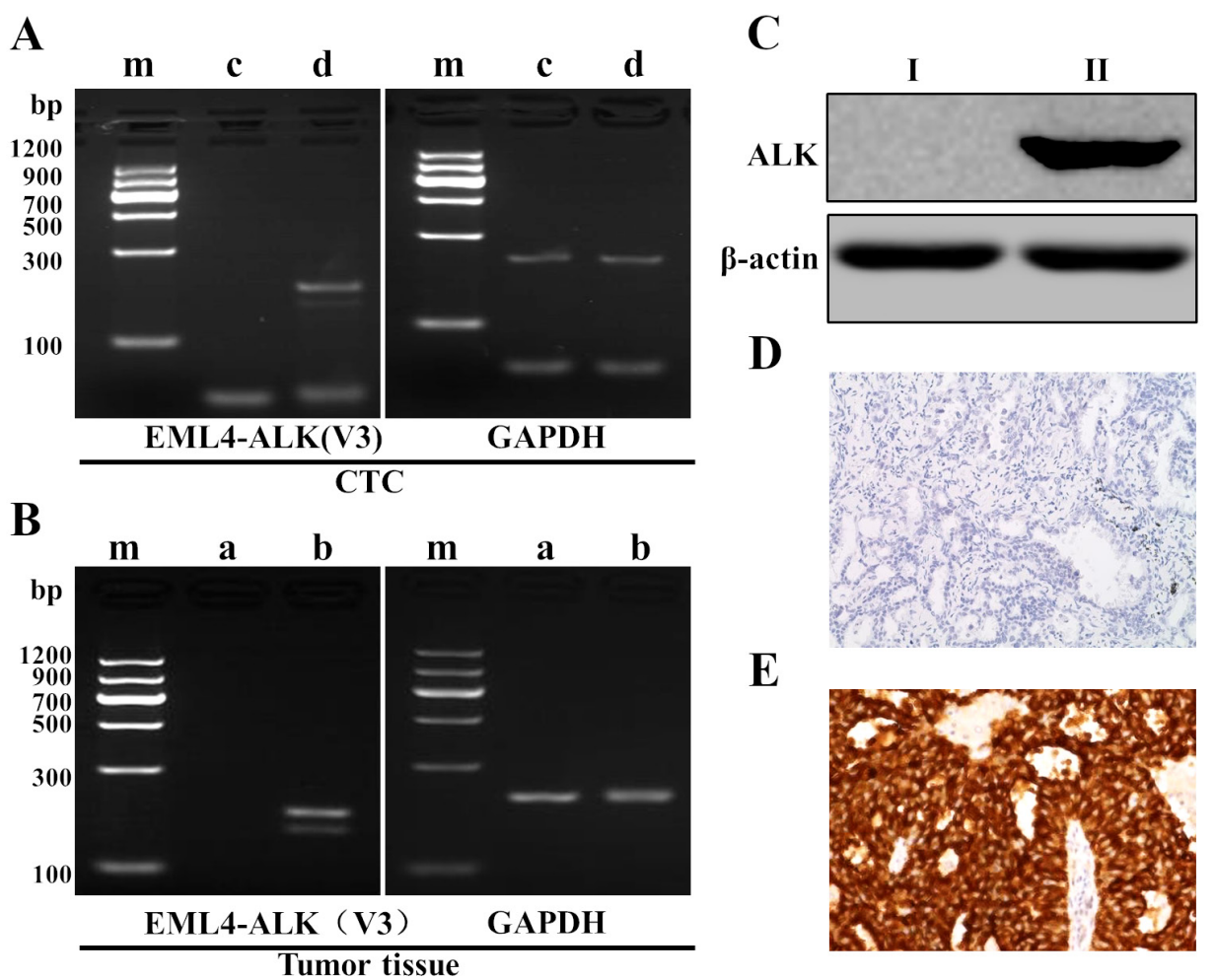

$\mathbf{E}$

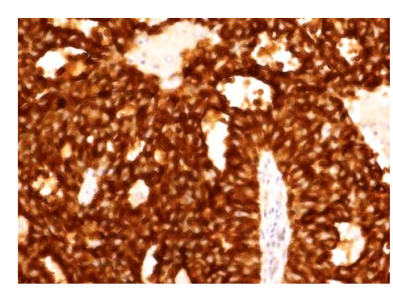

Figure 6. Detection results of the EML4-ALK fusion gene. A) Gene fusion results of EML4-ALK (V3) in tissue by RT-PCR detection (m: DNA marker, a: para-tumor tissue, b: tumor tissue). B) Gene fusion results of EML4-ALK (V3) in CTC by RT-PCR detection (m: DNA marker c: BEAS-2B cells, d: CTC). C) Western blot results of ALK protein in tissues (I: para-tumor tissue, II: tumor tissue); D) ALK-negative immunohistochemical results ( $\times 20$ ); E) ALK-positive immunohistochemical results $(\times 20)$.

Table 1. Relationship between the EML4-ALK fusion gene expression and clinicopathological parameters of patients.

\begin{tabular}{lccc}
\hline Clinicopathological parameter & $\mathbf{n}$ & PCR+(\%) & p-value \\
\hline Age (years old) & & & 0.008 \\
$\quad \leq 60$ & 33 & $15(25.00 \%)$ & \\
$\quad>60$ & 27 & $4(6.67 \%)$ & \\
Sex & & & 0.441 \\
$\quad$ Male & 39 & $11(18.22 \%)$ & \\
$\quad$ Female & 21 & $8(13.33 \%)$ & \\
Smoking history & & & 0.032 \\
$\quad$ Yes & 24 & $4(6.67)$ & \\
$\quad$ No & 36 & $15(25.00 \%)$ & \\
Pathological pattern & & & 0.026 \\
$\quad$ Adenocarcinoma & 44 & $17(28.33 \%)$ & \\
$\quad$ Non-adenocarcinoma & 16 & $2(3.33 \%)$ & \\
\hline
\end{tabular}

positive, with a mutation rate of $31.67 \%(19 / 60)$. The analysis results show that the EML4-ALK gene fusion occurred in the relatively younger patients, with the positive rate of ALK in patients $\leq 60$ years old being $25 \%$, and that in patients $>60$ years old being $6.67 \%, p=0.008$. The positive rates of ALK in smokers and non-smokers were $6.67 \%$ and $25 \%$, respectively, $\mathrm{p}=0.032$. In terms of the tumor histological types, the positive rate of ALK was $28.33 \%$ in adenocarcinoma patients and $3.33 \%$ in non-adenocarcinoma patients, $p=0.026$. The positive rate of ALK in male patients was slightly higher than that in female patients, but it is not statistically significant $(\mathrm{p}=0.441$, Table 1$)$.

The specific gene fusion results are shown in Figure 7. As can be seen from Figure 7A, the RT-PCR gene fusion detection results of CTCs captured in peripheral blood are consistent with the RT-PCR results of tissues; the positive rate of EML4-ALK gene fusion detected by western blot and IHC is slightly lower than that detected by RT-PCR, but there is no significant difference, indicating that the RT-PCR detection results of CTCs are highly consistent with the detection results of tissues by RT-PCR, WB, and IHC. It can also be seen from Figure 7B that EML4-ALK gene fusion includes four variant expression types, namely, EML4-ALK (V1), EML4-ALK (V2), EML4-ALK (V3), and EML4-ALK (V5), among which the positive rate of EML4-ALK (V3) is the highest, with a positive rate of about $15 \%$. The statistical results of 60 cases of pre-operative and post-operative EML4-ALK gene fusion are shown in Figure $7 \mathrm{C}$. The positive rate of pre-operative EML4-ALK gene fusion was 31.67\%; while the positive rate of post-operative EML4-ALK gene fusion, 28.3\%, was lower than that of pre-operative one. 


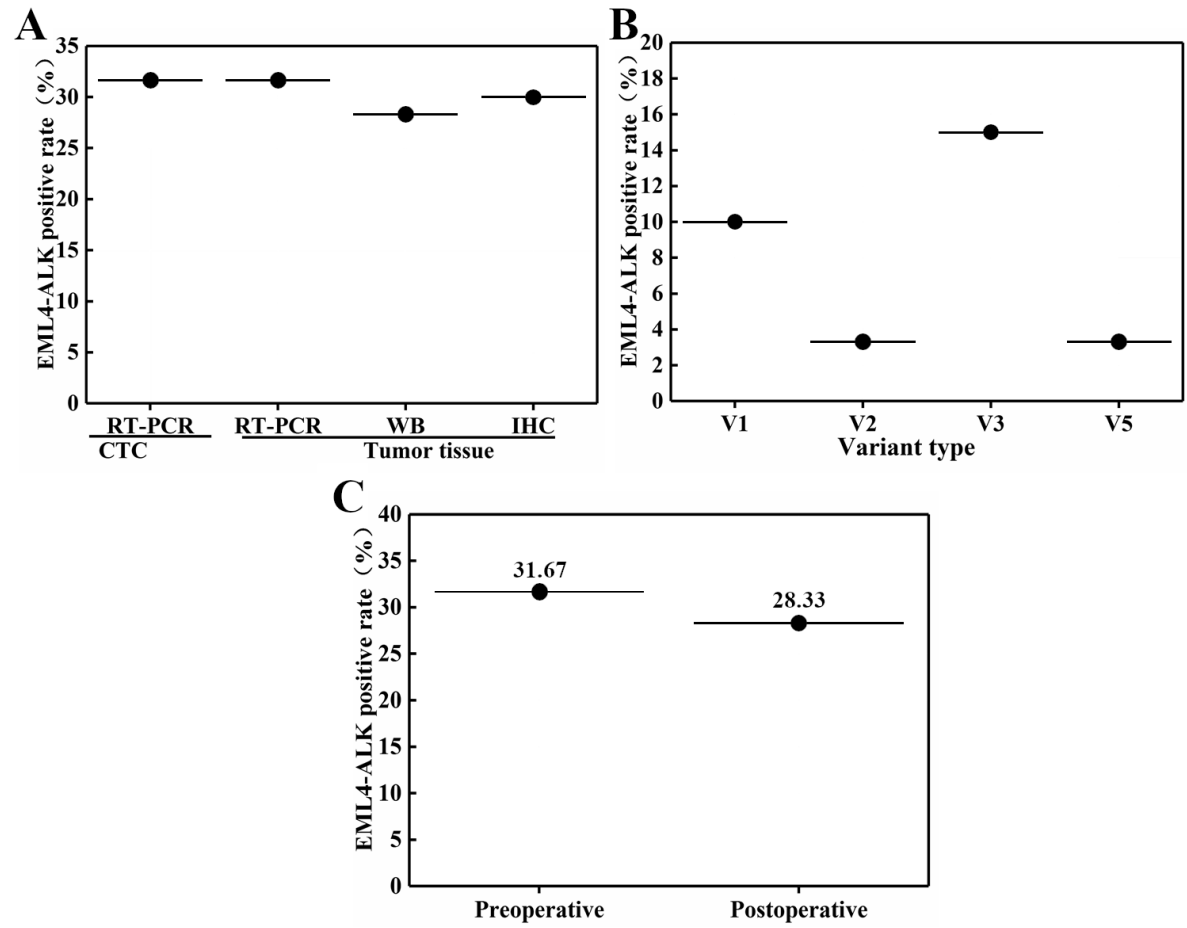

Figure 7. Statistical results of gene fusion: A) Consistency between RT-PCR results of CTC and RT-PCR, WB, and IHC results of tissues; B) EML4ALK-positive rate with different variant types; C) Pre-operative and post-operative EML4-ALK-positive rates.

\section{Discussion}

So far, the detection methods for ALK rearrangement include fluorescence in situ hybridization (FISH), immunohistochemistry (IHC), cDNA reverse transcription polymerase chain reaction (RT-PCR), and NGS, each of these has its advantages and disadvantages. At present, FISH is the "gold standard" for the detection of ALK fusion gene, which can detect all fusion subtypes accurately and reliably. FISH has become a standard diagnostic tool because it is recommended as a reference method in clinical trials or to confirm suspicious IHC results [13-15]. Nevertheless, FISH is expensive and time-consuming, and specialized fluorescence microscopes and specialists are required. In addition, FISH could be challenging because false negative and false positive results may exist and result in significant interobserver differences $[16,17]$. Another screening test for ALK protein is IHC [18], which is a sensitive and specific method to determine the expression of ALK protein and screen ALK fusion genes, which is characterized by low cost, short cycle, and easy operation [19]. RT-PCR can also detect ALK fusion genes at a lower price, without the subjective judgment of the testers. However, the detection methods above are mostly used for tissue detection, which will be difficult for the detection of lung cancer and other cancer tissues.

A method to capture CTCs from peripheral blood of patients and to perform gene detection by preparing immuno- magnetic beads was put forward based on this, to effectively solve the problem of difficult tissue acquisition. The acquisition methods of CTCs mainly include cell size enrichment method, gradient centrifugation method, and immunomagnetic bead method, etc. In the immunomagnetic bead separation method, the magnetic beads labeled by specific monoclonal antibody firstly bind to the surface antigen of the target cells, and then the target cells are separated from other cells in the blood under the action of the magnetic field. Studies have shown that compared with other methods, immunomagnetic bead separation could greatly improve the detection rate of circulating tumor cells in the blood [20]. As the first and only commercial product approved by FDA and CFDA, Cell Search also uses the EpCAM specific antibodybased magnetic bead separation method [21]. Moreover, as the gold standard for circulating tumor cell sorting, 5-1,000 circulating tumor cells could be detected from $7.5 \mathrm{ml}$ blood, which could be used as the prognosis evaluation of tumor patients. The VI-LMB, EP-LMB, and EGFR-LMB magnetic beads with small particle size, high stability, and strong specificity were successfully prepared, and the three kinds of magnetic beads showed high capture efficiency after the simulation of CTC capture experiment, with the capture efficiency greater than $80 \%$.

Regarding the mutation rates of EML4-ALK subtypes, the incidence of each subtype reported by different research was slightly different. Woo et al. detected the EML4-ALK fusion 
gene subtypes of 54 advanced NSCLC patients by FISH and found that the $\mathrm{V} 3$ variant was the most common type, accounting for $44.4 \%$, while V1 and V2 variants accounted for $33.3 \%$ and $11.1 \%$, respectively [22]. Lei et al. detected the EML4-ALK fusion gene subtypes in 61 advanced NSCLC patients by FISH and found that the V1 and V3 variants accounted for $36 \%$ and $29.5 \%$, respectively [23]. Woo et al. [22] found that the V3 variant was the most common, while Lei et al. [23] found the V1 variant was the most common. In addition, Mitiushkina et al. detected the genetic subtypes of 64 ALK-positive NSCLC patients by using RT-PCR and found that the V1 variant accounted for 52\%, and V3 variants accounted for 25\% [24]. Yoshida et al. detected EML4-ALK fusion gene subtypes in 35 NSCLC patients by RT-PCR and found that the V1 variant accounted for $54 \%$, V2 and V3 variants accounted for $14 \%$ and $12 \%$, respectively [25]. Yoshida et al. detected the EML4-ALK fusion gene subtypes in 35 NSCLC patients by RT-PCR, and found that V1 variant accounted for $54 \%$, while V2 and V3 variants accounted for $14 \%$ and $12 \%$, respectively [25]. Lv et al. analyzed the fusion subtypes of 31 advanced NSCLC patients with positive EML4-ALK fusion gene by means of NGS and found that the V1 variant accounted for about $42 \%$, while V3 and V2 variants accounted for $26 \%$ and $10 \%$, respectively [26]. Through the analysis of EML4-ALK fusion subtypes after the CTCs were captured in the blood of 60 lung cancer patients, it was found that the incidence of the V1 variant was $10 \%$, and those of $\mathrm{V} 3$ and V2 variants were $15 \%$ and $3.3 \%$, respectively, so V3 variant was the most common, which was consistent with the findings of Woo et al. [22]. In addition, it was found through the verification of EML4-ALK fusion gene in tissues by RT-PCR, western blot, and IHC that the results obtained by CTCs were highly consistent with those by RT-PCR, WB, and IHC.

In conclusion, the EML4-ALK gene fusion detection performed on the nucleic acid of CTCs, which were captured in the blood of the patients histologically tested to be EML4-ALK positive, showed that the EML4-ALK fusion gene could be detected by means of CTCs, and it could demonstrate that the CTC-ALK gene fusion detection system was successfully established in this research, which could avoid the problems of difficult sampling and post-sampling complications, and really achieve the minimally invasive biopsy, so it will provide a certain experimental reference for taking blood CTCs as the target of fusion gene detection for lung cancer patients in the future.

Acknowledgments: This work was supported by grants from the National Natural Science Foundation of China (81600048) and Fujian Natural Science Foundation (2017J01359).

\section{References}

[1] TORRE LA, BRAY F, SIEGEL RL, FERLAY J, LORTETTIEULENT J et al. Global cancer statistics, 2012. CA Cancer J Clin 2015; 65: 87-108. https://doi.org/10.3322/caac.21262
[2] CALABUIG-FARIÑAS S, JANTUS-LEWINTRE E, HERREROS-POMARES A, CAMPS C. Circulating tumor cells versus circulating tumor DNA in lung cancer-which one will win?. Transl Lung Cancer Res 2016; 5: 466-482. https://doi. org/10.21037/tlcr.2016.10.02.

[3] KANG Y, PANTEL K. Tumor cell dissemination: emerging biological insights from animal models and cancer patients. Cancer Cell 2013; 23: 573-581. https://doi.org/10.1016/j. ccr.2013.04.017

[4] CHIANG YT, WANG K, FAZLI L, QI RZ, GLEAVE ME et al. GATA2 as a potential metastasis-driving gene in prostate cancer. Oncotarget 2014; 5: 451-461. https://doi. org/10.18632/oncotarget.1296

[5] CAPP JP. Stochastic gene expression is the driving force of cancer. Bioessays 2011; 33: 781-782. https://doi. org/10.1002/bies.201100092

[6] LARSON CJ, MORENO JG, PIENTA KJ, GROSS S, REPOLLET $M$ et al. Apoptosis of circulating tumor cells in prostate cancer patients. Cytometry A 2004; 62: 46-53. https://doi. org/10.1002/cyto.a.20073

[7] CHOI YL, SODA M, YAMASHITA Y, UENO T, TAKASHIMA J et al. EML4-ALK Mutations in Lung Cancer That Confer Resistance to ALK Inhibitors. N Engl J Med 2010; 363: 1734-1739. https://doi.org/10.1056/NEJMoa1007478

[8] MANO H. The EML4-ALK oncogene: Targeting an essential growth driver in human cancer. Proc Jpn Acad Ser B Phys Biol Sci 2015; 91: 193-201. https://doi. org/10.2183/pjab.91.193

[9] TEIXIDÓ C, KARACHALIOU N, PEG V, GIMENEZCAPITAN A, ROSELL R. Concordance of IHC, FISH and RT-PCR for EML4-ALK rearrangements. Transl Lung Cancer Res 2014; 3: 70-74. https://doi.org/10.3978/j.issn.22186751.2014.02.02

[10] WANG Y, ZHANG J, GAO G, LI X, ZHAO C et al. EML4-ALK Fusion Detected by RT-PCR Confers Similar Response to Crizotinib as Detected by FISH in Patients with Advanced Non-Small-Cell Lung Cancer. J Thorac Oncol 2015; 10: 1546-1552. https://doi. org/10.1097/JTO.0000000000000668

[11] SHI Y, LI LZ, SUN JZ, ZHANG T, PENG J et al. Rapid detection of BCR-ABL fusion genes using a novel combined LUX primer, in-cell RT-PCR and flow cytometric method. Ann Hematol 2008; 87: 35-41. https://doi.org/10.1007/s00277007-0365-8

[12] AGUADO C, TEIXIDO C, GIMENEZ-CAPITAN A, DE LOS LLANOS GIL M, RODRIGUEZ $S$ et al. Analysis of EML4-ALK fusion transcripts in plasma and platelets to monitor response to crizotinib in EML4-ALK positive nonsmall cell lung cancer patients (NSCLC). Cancer Res 2017; 77: Abstract nr 1739. https://doi.org/10.1158/1538-7445. AM2017-1739

[13] SOLOMON B, BANG YJ, CAMIDGE DR, LAFRATE AJ, KWAK EL et al. 369 Timing of responses to crizotinib (PF02341066) in anaplastic lymphoma kinase (ALK)-positive patients with advanced non-small cell lung cancer (NSCLC). Ejc 2010; 8: 117-117. https://doi.org/10.1016/S13596349(10)72076-0 
[14] LINDEMAN NI, CAGLE PT, AISNER DL, ARCILA ME, BEASLEY MB et al. Updated Molecular Testing Guideline for the Selection of Lung Cancer Patients for Treatment With Targeted Tyrosine Kinase Inhibitors. Jour Thor Oncol 2018; 13, 323-358. https://doi.org/10.1016/j. jtho.2017.12.001

[15] LINDEMAN NI, CAGLE PT, AISNER DL, ARCILA ME, BEASLEY MB et al. Updated Molecular Testing Guideline for the Selection of Lung Cancer Patients for Treatment With Targeted Tyrosine Kinase Inhibitors: Guideline From the College of American Pathologists, the International Association for the Study of Lung Cancer, and the Association for Molecular Pathology. Arch Pathol Lab Med 2018; 142: 321-346. https://doi.org/10.5858/arpa.2017-0388-CP

[16] MARTIN V, BERNASCONI B, MERLO E, BALZARINI P, VERMI $\mathrm{W}$ et al. ALK testing in lung adenocarcinoma: technical aspects to improve FISH evaluation in daily practice. J Thorac Oncol 2015; 10: 595-602. https://doi. org/10.1097/JTO.0000000000000444

[17] SHOLL LM, WEREMOWICZ S, GRAY SW, WONG KK, CHIRIEAC LR et al. Combined Use of ALK Immunohistochemistry and FISH for Optimal Detection of ALK-Rearranged Lung Adenocarcinomas. J Thorac Oncol 2013; 8: 322-328. https://doi.org/10.1097/JTO.0b013e31827db604

[18] GARON EB, RIZVI NA, HUI R, LEIGHL N, BALMANOUKIAN AS et al. Pembrolizumab for the treatment of non-small-cell lung cancer. N Engl J Med 2015; 372: 2018 2028. https://doi.org/10.1056/NEJMoa1501824

[19] HERBST RS, BAAS P, KIM DW, FELIP E, PÉREZ-GRACIA JL et al. Pembrolizumab versus docetaxel for previously treated, PD-L1-positive, advanced non-small-cell lung cancer (KEYNOTE-010): arandomised controlled trial. Lancet 2016; 387: 1540-1550. https://doi.org/10.1016/S01406736(15)01281-7
[20] TING DT, WITTNER BS, LIGORIO M, JORDAN NV, SHAH AM et al. Single-cell RNA sequencing identifiesextracellular matrix gene expression by pancreatic circulating tumor cells. Cell Rep 2014; 8: 1905-1918. https://doi. org/10.1016/j.celrep.2014.08.029

[21] ZIGEUNER RE, RIESENBERG R, POHLA H, HOFSTETTER A, OBERNEDER $R$ et al. Isolation of circulating cancer cells from whole blood by immunomagnetic cell enrichment and unenriched immunocytochemistry in vitro. J Urol 2003; 169: 701-705. https://doi.org/10.1097/01. ju.0000038953.11811.82

[22] WOO CG, SEO S, KIM SW, JANG SJ, PARK KS et al. Differential protein stability and clinical responses of EML4-ALK fusion variants to various ALK inhibitors in advanced ALKrearranged non-small cell lung cancer. Ann Oncol 2017; 28: 791-797. https://doi.org/10.1093/annonc/mdw693

[23] Lei YY, Yang JJ, Zhang XC, Zhong WZ, Zhou Q et al. Anaplastic Lymphoma Kinase Variants and the Percentage of ALK-Positive Tumor Cells and the Efficacy of Crizotinib in Advanced NSCLC. Clin Lung Cancer 2016; 17: 223-231. https://doi.org/10.1016/j.cllc.2015.09.002

[24] MITIUSHKINA NV, TIURIN VI, IYEVLEVA AG, KHOLMATOV MM, FILIPPOVA EA et al. Variability in lung cancer response to ALK inhibitors cannot be explained by the diversity of ALK fusion variants. Biochimie 2018; 154: 19-24. https://doi.org/10.1016/j.biochi.2018.07.018

[25] YOSHIDA T, OYA Y, TANAKA K, SHIMIZU J, HORIO $Y$ et al. Differential Crizotinib Response Duration Among ALK Fusion Variants in ALK-Positive Non-Small-Cell Lung Cancer. J Clin Oncol 2016; 34: 3383-3389. https://doi. org/10.1200/JCO.2015.65.8732

[26] LV T, ZOU Q, SONG Z, LIU H, WANG Q et al. The correlation between crizotinib efficacy and molecular heterogeneity by next-generation sequencing in non-small cell lung cancer. J Thorac Dis 2018; 10: 2948-2959. https://doi. org/10.21037/jtd.2018.05.55 